\title{
A case series of masquerade postpartum haemorrhage
}

\author{
Oluwasomidoyin O. Bello*, Olatunji O. Lawal
}

Department of Obstetrics and Gynecology, University College Hospital, Ibadan, Oyo State, Nigeria

Received: 17 October 2018

Accepted: 12 November 2018

\section{*Correspondence: \\ Dr. Oluwasomidoyin O. Bello, \\ E-mail: bellodoyin@yahoo.com}

Copyright: (C) the author(s), publisher and licensee Medip Academy. This is an open-access article distributed under the terms of the Creative Commons Attribution Non-Commercial License, which permits unrestricted non-commercial use, distribution, and reproduction in any medium, provided the original work is properly cited.

\begin{abstract}
Postpartum hemorrhage (PPH) is an obstetric emergency with different causes. Management is directed towards the cause and can be medical or surgical. This is a case series report of four patients who presented to University College Hospital; Ibadan, Nigeria with PPH following emergency caesarean section (EMCS) with three performed for prolonged obstructed labour. All the cases had severe PPH, hemodynamic instability and presented 14 to 84 days post caesarean section. Surgical exploration revealed extension of caesarean incision into the uterine vessel with slipped ligature in two of them and bleeding vessel without ligature in the other two. Two had haemostasis secured with uterine artery ligation, one had repair of uterine incision extension while the 4th had hysterectomy. The length of hospital stay was 5 to 13 days. All recovered fully post-operatively and were discharge home in good clinical condition.
\end{abstract}

Keywords: Caesarean section, Postpartum haemorrhage, Surgical skill

\section{INTRODUCTION}

Postpartum hemorrhage $(\mathrm{PPH})$ is a leading cause of maternal morbidity and mortality worldwide and commonly defined as blood loss of more than $500 \mathrm{ml}$ following vaginal delivery or more than $1000 \mathrm{ml}$ following cesarean section (CS) ${ }^{1,2}$ In developing countries where anaemia is prevalence, any bleeding that is enough to compromise the woman's haemodynamic stability is more representative. Globally, an estimate of 127,000 women die from obstetric haemorrhage and it contributes $30 \%$ to maternal death in Africa making it the highest singular cause of maternal mortality. ${ }^{2-5}$ This burden is the same in Nigeria where PPH contributes about $23.3 \%$ of maternal death largely due to poor health seeking behavior, unskilled birth attendants, poor health services and limited access to quality health services. ${ }^{5}$ PPH can be anticipated and prevented however, majority are unpredictable. Good practices with high index of suspicion based on the predisposing factors are key to its prevention. Risk factors include operative delivery, chorioamnionitis, precipitate labour, over distended uterus-multiple pregnancy, polyhydraimnois, fibroid, however PPH may occur among patient with no known risk factors. ${ }^{6}$ Although the leading cause is uterine atony other causes like retained products of conception, genital tract trauma (vaginal and cervical laceration), uterine rupture, uterine inversion or maternal coagulation disorders should also be considered. ${ }^{6,7}$ Even though, extension of the uterine incision into the angle and uterine vessels is not often considered as a major cause, if it occurs it can lead to excessive bleeding. Once PPH is diagnosed, early diagnosis and management must be instituted to prevent complications, such as hypovolemic shock, renal failure, disseminated intravascular coagulation, hepatic dysfunction and acute respiratory distress syndrome. ${ }^{7}$ Management of PPH depends largely on the cause, type of delivery, amount of bleeding, source of bleeding, hemodynamic stability, reproductive desire, skill of the obstetrician and available facilities like radiological intervention. ${ }^{1}$ 
In Nigeria, CS rate has increased due to increase literacy, medico legal intimidation, safer anesthesia and antibiotics and increase in primary $\mathrm{CS} .^{8}$ Moreover, CS significantly increases the risk of PPH especially in women with a previous history of CS. Despite this increase there is still paucity of material resources and skilled surgeons that can perform the procedure effectively especially in the face of surgical challenges such as impacted fetal head in prolonged obstructed labour, second stage CS and ruptured uterus with an upsurge of iatrogenic injuries like bladder injury, ureteric injury, intra and post-operative hemorrhage, unplanned hysterectomy. ${ }^{9}$

With increased incidence of $\mathrm{CS}$, there will be associated increase complications of the procedure; this is a case series of CS complicated with PPH with diagnostic oversight causes.

\section{CASE REPORT}

\section{Case 1}

Mrs. AC, 36-year-old $\mathrm{P}^{+1}$ (1 alive) who presented with recurrent bleeding per vagina (PV) of two weeks following EMCS done for prolonged obstructed labour in a private hospital. She had two episodes of severe bleeding PV each episode estimated to be $>1.5$ liters on the $4^{\text {th }}$ and $10^{\text {th }}$ day post-op. She had been transfused with four units of blood. She was pale, in shock with pulse of 132 per minute, blood pressure was unrecordable, abdomen was mildly distended, pfannestiel scar with generalize tenderness. On vaginal examination, the cervix was smooth, about $2 \mathrm{~cm}$ dilated, active bleeding from the uterine cavity. Packed cell volume (PCV) was $18 \%$, electrolytes and urea, urinalysis, clotting profile were normal, full blood count was not suggestive of infection, ultrasound showed an empty uterine cavity with significant haemoperitoneum. An assessment of secondary PPH secondary to scar uterine dehiscence. She was resuscitated and had non-pneumatic antishock garment (NASG) applied. She had exploratory laparotomy with intra-operative finding of dehiscence of the right lateral extension of transverse uterine incision into the right uterine artery and loosed ligature on the bleeding right uterine artery. The right uterine artery was ligated, haemostasis secured and dehiscence area repaired. She recovered well post-operatively and was discharged home on the $13^{\text {th }}$ post-operative day.

\section{Case 2}

Mrs. II, 28 years old $\mathrm{P} 1^{+0}(1$ alive $)$ who presented with recurrent vaginal bleeding of 4 weeks duration, following CS done on account of prolonged obstructed labour in a private hospital. Bleeding PV started a week postoperatively with associated dizziness and fainting spells. There was history of fever which subsided after about five days. She reported three episodes of torrential bleeding PV with associated clots on the $7^{\text {th }}, 14^{\text {th }}$ and $20^{\text {th }}$ day post-op and had oxytocics, antibiotics and four units of blood transfused. Manual vacuum aspiration (MVA) was done following the $2^{\text {nd }}$ episode of bleeding PV at the referral center.

She presented two hours after the $3^{\text {rd }}$ episode of bleeding PV. She was pale with a pulse of 110 per minute, blood pressure of $100 / 60 \mathrm{mmHg}$, abdomen was full, healing pfannenstiel scar, non tender with uterine size of 14 weeks. Vaginal examination revealed a blood smeared perineum, $100 \mathrm{mls}$ of clot evacuated from the vagina, cervix was closed and there was no acute bleeding. An assessment of secondary PPH secondary to likely endometritis to keep in view slipped ligature. She was resuscitated and commenced on oxytocics, tranexamic acid and antibiotics. Electrolytes and urea, urinalysis, clotting profile were normal, PCV $-24 \%$, full blood count was not suggestive of infection, ultrasound showed empty uterus and no haemoperitoneum.

On admission, she had two episodes of bleeding PV estimated to be about $500 \mathrm{mls}$ and $600 \mathrm{mls}$ with a pulse of 120 beats per minute and blood pressure of $80 / 40 \mathrm{mmHg}$. She was resuscitated, had NASG applied. She had vaginal and cervical exploration with an incision seen on the cervix extending into the uterine cavity. Abdominal intra-op findings of adhesion between the bladder and uterus, extension of cesarean incision anteriorly into the cervix which was bleeding into the vagina. This was repaired per abdomen and vaginally with haemostasis secured. She recovered well and was discharge home on fifth day post op.

\section{Case 3}

Mrs. OT, 29-year-old $\mathrm{P}^{+3}$ (2 alive) who presented with recurrent vaginal bleeding of 12 weeks duration following CS done on account of severe oligohydraminous and post datism and was transfused with 5 units of blood due to primary PPH in a government hospital (secondary health facility). She has been bleeding PV since delivery with two profuse bleeding episodes on the $2^{\text {nd }}$ and $8^{\text {th }}$ weeks post-op. She had oxytocics, antibiotics, manual vacuum aspiration and was transfused with nine units of blood. At presentation, she was pale with a pulse of 124 per minute, blood pressure of $100 / 60 \mathrm{mmHg}$, abdomen was full, pfannenstiel scar with uterine size of 14 weeks. Vaginal examination revealed a blood smeared perineum, cervical os was closed with no acute bleeding. An assessment of secondary PPH secondary to slipped ligature to keep in view gestational trophoblastic disorder (GTD). She was resuscitated and commenced on oxytocics, tranexamic acid and antibiotics. PCV $-21 \%$, full blood count was not suggestive of infection, Ultrasound revealed essentially normal findings, electrolytes and urea, urinalysis, clotting profile, serum B-HCG were normal.

Intra-operative findings of $4 \mathrm{~cm}$ left uterine angle dehiscence and active bleeding from left uterine artery. The left uterine artery was ligated, haemostasis secured 
and dehiscence area was freshened and repaired. She recovered well post operatively and was discharged home on the sixth post-operative day.

\section{Case 4}

Mrs. ZF, 38-year-old P2 ${ }^{+2}$ (2 alive) who presented with recurrent bleeding $\mathrm{PV}$ of two weeks duration following EMCS performed on account of obstructed labour. There was PPH intra-operatively for which she had three units of blood transfused. Bleeding started on the third day after delivery and increased in severity each subsequent day with breakthrough heavy bleeding PV of two episodes estimated to be about $500 \mathrm{mls}$ and $800 \mathrm{mls}$ respectively. Associated history of high-grade fever and offensive lochia. She was pale with a pulse of 108 beats per minute and blood pressure of $100 / 60 \mathrm{mmHg}$. The abdomen was full with grade 2 pfanniestiel wound infection and a uterine size of 18 weeks. Vaginal examination revealed a blood smeared perineum, cervical os was closed with no acute bleeding. An assessment of secondary PPH secondary to endometritis. The obstetrics team ruled out retained placental tissue, uterine atony and gestational trophoblastic disease. Ultrasound showed bulky uterus with multiple fibroid and no retained products or haemoperitoneum.

Full blood count showed leukocytosis-21,000/ $\mathrm{mm}^{3}, \mathrm{PCV}-$ $15 \%$, urinalysis, serum B-HCG, clotting profile, electrolyte and urea were normal, high vaginal and endocervical swabs culture yielded no growth. She had intravenous antibiotics and was transfused with 3 units of blood. She had 2 more episodes of profuse vaginal bleeding on admission estimated to be 1 and 1.2 liters respectively at 9 days interval. An assessment of uterine subinvolution with possible infected fibroid was entertained. At each episode she was resuscitated and had oxytocics, misoprostol, tranexamic acid and transfused with blood. She had NASG applied at the $1^{\text {st }}$ episode of bleeding because she was in hypovolaemic shock. Active bleeding PV subsides after each acute episodes of profuse bleeding.

She had exploratory laparotomy after the $2^{\text {nd }}$ episode with intra-op findings of multiple uterine fibroids, intact uterine scar, and exploration of the uterine cavity reveal a large submucous fibroid nodule on the posterior endometrial cavity with active bleeding from the surface. There was difficulty in performing myomectomy and securing haemostasis because the uterine muscles were friable. Subtotal hysterectomy was performed. She recovered well after the surgery and was discharge home on the sixth day post-op.

\section{DISCUSSION}

PPH is a significant cause of morbidity in our environment; prompt recognition and effective management reduce the risk of maternal mortality. The cases presented highlight the need to be vigilant to other unusual causes of PPH which can easily be overlooked while considering the major causes grouped as 4Ts - tone, tissue, thrombosis and trauma. The case series fall in the trauma group.

In managing PPH, a step wise approach which focuses on preventing further blood loss, restoring effective blood volume and treating the primary cause of the bleeding is instituted. Medical therapy is first initiated and if it fails, organ-sparing surgical intervention is instituted with hysterectomy as the last option however this depends largely on the surgeon's skills. ${ }^{10}$ In this case series, three had organ-sparing surgery with uterine artery ligation and ligation of the bleeding vessel while one had hysterectomy because the uterus was riddled with multiple fibroids with bleeding surfaces and friable uterine muscles. Although, management of PPH and its effects is crucial but more importantly is for clinicians to recognize its risk factors and implement precautions to prevent it in all pregnant women.

In this case series, the causes of PPH are all potentially avoidable causes during cesarean delivery if the surgeon acquires adequate surgical skills or recognizes his/her limitations and call for help early when needed. All the cases presented survived with adequate management however, one woman had a morbidity of hysterectomy. Though, severe PPH is a major cause of maternal mortality in Nigeria. ${ }^{11}$

One of the cases was referred from a government secondary health facility while the remaining three were from private hospitals and the CS was done in the hospitals respectively. These cases were delayed for 14 to 84 days before referral. Surprisingly, the third case was no more in the puerperal period. Other identified concerns about this case series include inadequate surgical skills and poor clinical judgment in diagnosing the cause of PPH. These were also the findings and concerns in a study by Salome et al where increase death following CS was reported. ${ }^{12}$ Therefore, this calls for strengthening of the maternal healthcare systems with increase clinical vigilance, rapid effective response to $\mathrm{PPH}$ along with quick and efficient referral system.

In a study in South Africa some of the identified causes of death following CS were delay in performing second look surgery, failure to detect hypovolemic shock, failure to control bleeding and/or treat shock, unavailability of blood which was not the case in three cases presented and this could have accounted for their survival and prompt recovery. ${ }^{12}$ However, there was a delay in a second look surgery in case four due to diagnostic over sight but she recovered well because of the prompt resuscitation at each episode of bleeding and the available experience surgical skills. All the cases above were promptly and adequately resuscitated and their shock treated. Also, NASG which shunt blood away from the lower extremities to vital organs was used and this contributed to the survival of the patients. ${ }^{13}$ 


\section{CONCLUSION}

Conclusively, in the event of surgical task shifting to reduce maternal and fetal morbidities and mortalities while ensuring availability of emergency obstetric care (EmOC), it is pertinent to train the medical officers and non-specialist surgeons on management of difficult cesarean deliveries especially with the current increase in the incidence of primary CS. More attention should be placed on increasing the knowledge and skills of surgeons which are crucial to the quality of care not only focusing on the availability and accessibility of EmOC.

Funding: No funding sources Conflict of interest: None declared

Ethical approval: Not required

\section{REFERENCES}

1. American College of Obstetricians and Gynecologists. ACOG practice bulletin: clinical practice guidelines for obstetricians gynecologists: postpartum hemorrhage. Obstet Gynecol. 2006;108(4):1039-47.

2. Camuzcuoglu H, Toy H, Vural M, Yildiz F, Aydin $H$. Internal iliac artery ligation for severe postpartum hemorrhage and severe hemorrhage after postpartum hysterectomy. J Obstet Gynaecol Res. 2010;36(3):538-43

3. Khan KS, Wojdyla D, Say L, Gülmezoglu AM, Van Look PF. WHO analysis of causes of maternal death: a systematic review. Lancet. 2006;367(9516):106674

4. World Health organization, author. Reducing the global burden: Postpartum haemorrhage. 2008. Available

at: http://www.who.int/making_pregnancy_safer/docum ents/newsletter/mps_newsletter_issue4.pdf.

5. Oguntoyinbo AE, Amole AOD, Aboyeji AO. Relationship between normally implanted placenta and estimated postpartum blood loss. West Afr J Ultrasound. 2003;4(1):20-4.
6. Bateman BT, Berman MF, Riley LE, Leffert LR. The epidemiology of postpartum hemorrhage in a large, nationwide sample of deliveries. Anesth Analg. 2010;110(5):1368-73.

7. Edhi MM, Aslam HM, Naqvi Z, Hashmi H. Post partum haemorrhage: causes and management. BMC Res Notes. 2013;6:236-7.

8. Dutta DC. Operative Obstetrics. In: Textbook of Obstetrics. $6^{\text {th }}$ ed. New central book Agency (P) Ltd: Calcutta, India; 2004:588-597.

9. Litorp H, Kidanto HL, Rööst M, Abeid M, Nyström L, Essén B. Maternal near-miss and death and their association with caesarean section complications: a cross-sectional study at a university hospital and a regional hospital in Tanzania. BMC Preg Childbirth. 2014; $14: 244$.

10. Kong MC, To WW. Balloon tamponade for postpartum haemorrhage: case series and literature review. Hong Kong Med J. 2013;19(6):484-90.

11. WHO (World Health Organization). Trends in Maternal Mortality: 1990 to 2015. Estimates by WHO, UNICEF, UNFPA, the World Bank and the United Nations Population Division. Geneva: WHO. $2015 . \quad$ Available at: www.who.int/reproductivehealth/publications/monit oring/maternal-mortality-2015/en/.

12. Salome M, Eckhart B. Causes and avoidable factors in maternal death due to cesarean-related hemorrhage in South Africa. Int $\mathbf{J}$ Gynecol Obstet. 2016;134(3):320-3.

13. Pileggi-Castro C, Nogueira-Pileggi V, Tuncalp O, Oladapo OT, Vogel JP, Souza JP. Non-pneumatic anti-shock garment for improving maternal survival following severe postpartum haemorrhage: a systematic review. Reprod Health. 2015;12:28.

Cite this article as: Bello OO, Lawal OO. A case series of masquerade postpartum haemorrhage. Int J Reprod Contracept Obstet Gynecol 2018;7:5165-8. 